\title{
Multiple Myeloma-lgD
}

National Cancer Institute

\section{Source}

National Cancer Institute. Multiple Myeloma-IgD. NCI Thesaurus. Code C70607.

The heavy chain of the immunoglobulin, IgD, is defective. This multiple myeloma subtype is very rare $(\sim 1 \%)$. 